\title{
Docência na Educação Infantil: origens de uma constituição profissional feminina
}

Resumo: O presente trabalho visa apresentar um conjunto de pesquisas cujo objetivo principal tem sido analisar a definição da docência na Educação Infantil e a própria construção conceitual acerca da especificidade das funções da educação da pequena infância. O estudo sobre as profissionais da Educação Infantil, suas funções, ação docente e relações entre diferentes profissionais na educação da criança foi inaugurado principalmente com Cerisara (1996) e Sayão (2005) que, em suas teses, trataram das contradições entre o feminino e o profissional, da identidade das professoras e professores e das dimensões de gênero envolvidas nestas funções e nas relações de trabalho junto às crianças pequenas. A preocupação em compreender as bases que constituem esta profissão, sua identidade e gênero, alia-se às preocupações com as origens históricas desta docência. Nesta direção, os estudos de Rocha (2012) e Batista (2013) ampliam o foco da pesquisa da profissionalização para a emergência da docência, produzindo novos questionamentos críticos e de investigações sobre o processo histórico que constitui a docência na Educação Infantil.

Palavras-chave: Educação Infantil. Docência. Relações de Gênero.

\section{Teaching in Early Childhood Education: origins of women professional constitution}

\begin{abstract}
This work aims to present a set of studies which the main goal is to analyze the definition of teaching in Early Childhood Education and also the conceptual construction about the specificities of the role on the issue of teaching in childhood. The study about the professionals of Early Childhood Education, their roles, educational action and the differences among professionals in the education of the children was inaugurated especially with Cerisara (1996) and Sayão (2005) who, in their theses, dealt with the contradictions between women and professionals, the identity of the teachers and the notions of gender involved in the functions and in the relations of work next to the small children. The concern in understanding the bases of this profession, its identity and gender, is allied to the concerns with historical origins of this teaching. In this way, the studies of Rock (2012) and Batista (2013) broaden the focus of the research about professionalization for the emergency of teaching, generating new critical questionnaires and investigations about the historical process that constitutes the teaching in Early Childhood Education.
\end{abstract}

Keywords: Early Childhood Education. Teaching. Gender relations.

\footnotetext{
1 Doutora em Educação pelo Programa de Pós-Graduação em Educação da UFSC. Pós-doutoranda PNPD/CAPES do Programa de Pós-Graduação em Educação da Universidade do Sul de Santa Catarina (UNISUL). E-mail: rosab@terra.com.br

2 Doutora em Educação pela Universidade Estadual de Campinas. Professora aposentada da Universidade Federal de Santa Catarina, onde atua com colaboradora no PPGE, na linha Educação e Infância e é professora permanente do PPGE da UNOESC SC. E-mail: eloisa.rocha@ufsc.br
} 


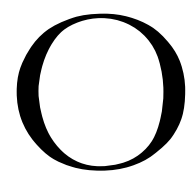

presente texto propõe uma breve reflexão referente aos estudos sobre a docência na Educação Infantil que apresentam as dimensões de gênero como constitutivas da profissão docente e das relações educativas junto às crianças pequenas nos contextos da Creche e Préescola. Esses estudos 3 inserem-se no âmbito de uma Pedagogia da Infância. Esta subárea vem se constituindo a partir de uma acumulação científica na direção de uma crítica às bases educacionais e pedagógicas, tradicionalmente consolidadas como orientadoras da educação das crianças desde a Educação Infantil, e busca a afirmação de perspectivas pedagógicas e de conhecimento orientado para a infância e sua educação em uma dimensão social e cultural. Nesta perspectiva, os estudos têm buscado uma consolidação conceitual particular em torno das especificidades das funções da educação da pequena infância relacionada à análise das definições da docência, suas origens, delimitações e suas relações profissionais.

A variedade de funções profissionais envolvidas nas ações educativas em Creches e em Préescolas, assim como certa indefinição das categorias profissionais atuantes neste nível educacional, derivam das origens e trajetórias distintas destas instituições e de suas reconfigurações, também advindas da integração ao sistema educativo. A necessidade de aprofundar o conhecimento sobre estas configurações profissionais exige a aproximação com estudos sobre a docência, na medida em que vai se definindo, também, em termos de conquista legal, a profissão de professora de Educação Infantil.

No enfrentamento da tarefa de constituição da área da Educação Infantil como um segmento da Educação Básica, que tem suas especificidades, tem-se procurado construir referências, para a docência, orientadas pela complexidade das ações da educação das crianças pequenas, na medida em que o seu desenvolvimento cognitivo, afetivo, físico, social, e cultural é concebido como um processo marcado por diferentes dimensões imersas no interior das relações entre adultos e crianças, e das crianças entre si. Não obstante, compreender as dimensões especificamente pedagógicas do trabalho docente na educação de 0 a 6 anos continua sendo um desafio, pois, como indicam Mantovani e Perani (1999), educador(a) da primeira infância é uma profissão em construção. Uma profissão que desenvolve atividades relativas ao educar e ao cuidar de forma indissociável e complementar à família ainda ocasiona tensões no que diz respeito à influência das experiências maternas e domésticas no contexto educacional-pedagógico, dificultando a consolidação de uma cultura própria e específica da profissão.

\footnotetext{
${ }^{3}$ Os estudos vinculam-se ao Grupo de Pesquisa NUPEIN/CED/UFSC.
} 
Este segmento profissional ainda depende de melhores definições de suas funções no âmbito das instituições educativas, e vem exigindo maior conhecimento de suas origens e de seu percurso histórico. Estudos realizados por pesquisadores nacionais e internacionais da área da educação também indicam a necessidade de pensar a ação docente em uma perspectiva mais ampla, enfatizando que a constituição profissional das professoras que atuam na Educação Infantil tem sido objeto recorrente de estudos, sinalizando que essa formação apresenta hiatos no que diz respeito ao que lhe é próprio e particular.

Dentre os estudos que têm como foco estas profissionais, com maior atenção à sua formação e à definição do caráter educativo da Educação Infantil, podemos citar Rocha (1999; 2007; 2012); Faria (1999); Mantovani e Perani (1999); Rivero (2001); Kramer (2002); Cerisara (2002); Kishimoto (2002); Formosinho (2002); Bonetti (2004); Oliveira (2006); Fernandes (2010); Duarte (2011); Albuquerque (2013); Tristão (2004); Schmitt (2014), entre outras. Essas autoras apresentam importantes indicações sobre a formação e a maioria delas indica a necessidade de ampliar o conhecimento sobre o que constitui a especificidade da docência na Educação Infantil.

Os desafios atuais sobre a definição de qual é o(a) profissional que atuará na Educação Infantil, em que condições deverá trabalhar e como deve ser formado(a) estão imersos na

[...] ausência de consenso, associada à falta de claras referências de perfil profissional e de uma trilha comum a seguir na construção dessa profissionalidade, [que] deve-se tanto a fatores externos, relacionados com a origem e o desenvolvimento das instituições de cuidado e educação da criança pequena, quanto a fatores inerentes às atividades voltadas à infância (HADDAD; CORDEIRO; MONACO, 2012, p. 136).

A constituição da docência no âmbito da Educação Infantil pressupõe levar em consideração o papel das relações de gênero e suas implicações na construção da identidade profissional, suas determinações, no que se refere à feminização, e as contradições que dela decorrem. Nesse sentido, destacam-se neste texto os estudos produzidos sobre a docência na Educação Infantil que focalizam as relações de gênero envolvidas na sua constituição histórica e nos processos de construção da identidade profissional. Para tanto, propomos dois momentos de discussão: uma breve reflexão em torno da identidade, relações de gênero e trabalho docente; e uma problematização sobre a emergência de uma constituição profissional feminina.

\section{Identidade, relações de gênero e trabalho docente}

Os estudos sobre as(os) profissionais da Educação Infantil, relações entre diferentes profissionais, suas funções e ação docente na educação da criança foram inaugurados com Cerisara (1996) e Sayão (2005). Em suas teses, essas autoras trataram da identidade dos professores, professoras, auxiliares de sala e das dimensões de gênero envolvidas nessas funções e nas relações de trabalho junto às crianças pequenas. São pesquisas que apresentam questões comuns que atualmente ainda pautam os debates em torno da identidade dos(as) profissionais e da especificidade da docência na Educação Infantil.

O estudo de Cerisara (1996), intitulado A construção da identidade das profissionais de Educação Infantil: entre o feminino e o profissional, buscou ampliar o debate acerca da construção da identidade das professoras 
de Educação Infantil, sua identidade de gênero e profissional, para compreender como se relacionam as práticas femininas domésticas e a prática profissional das mulheres que trabalham em Creches e Préescolas. A análise realizada na pesquisa é construída a partir da positividade dessas configurações femininas de relacionamento e de organização do trabalho das profissionais, em especial, contrariando a ideia de que todo trabalho feminino que guarda características de trabalho doméstico é negativo em si, porque excludente de uma formação técnica (CERISARA, 1996, p.161).

A pesquisa realizada por Sayão (2005), Relações de gênero e trabalho docente na Educação Infantil: um estudo de professores em Creche, analisou a trajetória profissional e do cotidiano de homens em atuação em Creches públicas, tomando como categoria central as relações de gênero. Uma das contribuições desse estudo reside na análise das trajetórias de homens que se constituem como professores de Educação Infantil, em uma perspectiva relacional, as masculinidades $\mathrm{e}$ as feminilidades como elementos significativos para o trabalho docente, concebendo-os como interdependentes e constitutivos das relações sociais. Compreender como os homens constituem-se professores de Educação Infantil representa pôr em confronto as relações que envolvem as dimensões de cuidado naturalizadas como funções femininas, que conformam uma espécie de cultura institucional. Nesse sentido é importante reafirmar que

Os modelos socialmente construídos de mulheres "cuidadoras" e homens "provedores" talvez tenham contribuído para gerar nas profissionais a aposta de que os docentes "não dariam conta do recado", tendo em vista que são elas que historicamente e desde a infância aprendem "como cuidar". Ou seja, parecia haver uma legitimidade nas práticas exercidas pelas mulheres ratificadas pelo argumento da feminilidade como características inatas em face de seus antecedentes como mães ou como "cuidadoras" de outras crianças no âmbito doméstico ou mesmo em experiências anteriores em instituições educativas para a infância (SAYÃO, 2005, p. 177).

Cerisara (1996) e Sayão (2005) apresentam importantes contribuições e indicam a necessidade de ampliar o conhecimento sobre a definição e perfil profissional relacionado à docência na Educação Infantil, sobretudo quando fazem referência à especificidade deste nível educacional. Advertem que a definição do papel das professoras de Educação Infantil, que se contrapõe ao das professoras do Ensino Fundamental, exige melhor compreensão da especificidade do trabalho com os bebês e crianças pequenas. Neste sentido, é importante considerar que "as práticas dessas profissionais são práticas que se mesclam com as práticas domésticas e de maternagem, as quais são socialmente desvalorizadas" (CERISARA, 2002, p. 107). Nesta mesma direção, Sayão (2005) reitera que esta é uma profissão que carece de melhores definições, e destaca a necessidade de elucidar as dimensões que constituem o cuidar/educar e o perfil do professor ou professora, tendo em vista a valorização da cultura infantil.

A constituição histórica da Educação Infantil, marcada pelas contradições entre o feminino e o profissional, e o discurso da maternidade como função primordial das mulheres na educação e socialização das crianças no âmbito doméstico tem contribuído para potencializar a negatividade das práticas que constituem a maternagem sobre práticas reconhecidas como pedagógicas. O estudo de Cerisara(2002, p. 160) evidenciou elementos que se interpõem nessa relação:

[...] a identidade dos diferentes papéis de mãe-profissional de creche-professora, vivem conflitos relativos à simultaneidade de identidades destes diferentes papéis, assim como 
percebem uma contaminação das práticas femininas domésticas nas práticas que desenvolvem trabalhando diretamente com as crianças de 0a6anos, as quais devem ter garantidos seus direitos fundamentais através do desenvolvimento de atividades ligadas ao cuidado e educação.

A reflexão realizada por Cerisara (2002), problematiza as dimensões da maternagem e do trabalho doméstico na interface com as dimensões profissionais, considerando que não são excludentes, mas constitutivas do trabalho pedagógico realizado, em especial com os bebês. Alimentar, banhar, trocar fraldas, ninar, acariciar, consolar, entre outras, são

tarefas que estão muito mais próximas das atividades desenvolvidas por mulheres em práticas domésticas não profissionais do que do trabalho das professoras em escolas, tal como concebido pelo senso comum e pela maioria das professoras (CERISARA, 2002, p. 63).

Aqui também reside uma indefinição sobre o valor social e educativo da Educação Infantil e, consequentemente, sobre a especificidade da docência nesta modalidade de educação. Ao se conferir às profissionais que atuam na Educação Infantil a legalidade da denominação professora ${ }^{4}$, criou-se a legitimidade profissional e a consequente valorização do trabalho realizado com as crianças de 0 a Ganos. Isto, de certo modo, alimentou o caráter educacional valorizado pela racionalidade, cientificidade, objetividade e característica do modelo escolar. Cerisara (2002, p. 63) constata, em sua pesquisa, que

a comparação educação infantil-escola é uma constante e, em alguns casos, somente a proximidade com o caráter escolar-formal daria ao trabalho realizado nas instituições de Educação Infantil pelas professoras uma legitimidade de trabalho competente e profissional, em que não houvesse risco de cair na substituição materna.

As professoras de Educação Infantil percebem e vivem, no contato diário com as crianças, relações que se aproximam das práticas brincantes, afetivas, emocionais, corporais, festivas e de cuidado; vivem cotidianamente imersas em um ambiente majoritariamente feminino, além do convívio com as famílias, cuja proximidade é distinta dos espaços escolares. Nesse contexto, as dimensões da maternagem, tanto quanto as do trabalho doméstico, revelam-se indissociáveis das dimensões constitutivas da docência. Portanto, as práticas educativo-pedagógicas constituem-se a partir de um conjunto de conhecimentos nos quais se mesclam experiências domésticas, experiências oriundas das práticas pedagógicas e aquelas adquiridas nos cursos de formação inicial e continuada. Importante considerar que as experiências domésticas e maternais também podem ser mobilizadoras das práticas profissionais, na perspectiva do que afirma Tardif (2008, p. 38-39) sobre os saberes experienciais:

[...] os próprios professores, no exercício de sua profissão, desenvolvem saberes específicos, baseados no seu trabalho cotidiano e no conhecimento do seu meio. Esses saberes brotam da experiência e são por elas validados. Eles incorporam-se à experiência individual e coletiva sob forma de habituse de habilidades, de saber-fazer e de saber-ser. Podemos chamá-los de saberes experienciais ou práticos.

Contudo,

a necessidade de enfrentar a relação dessas dimensões que ainda se entrecruzam remete à formação dessas profissionais, seja numa formação inicial, seja em serviço, que inclua

${ }^{4}$ Esta legalidade foi assegurada pela Lei de Diretrizes e Bases da Educação Nacional (LDB 9.394/1996), que define, em seu artigo 62, a exigência de formação mínima em Ensino Médio, modalidade normal. 
a pedagogia da Educação Infantil como objeto de reflexão [...] (CERISARA, 2002, p. 68).

A definição dessa profissão exige reconhecer a existência de ambiguidades no exercício de um magistério compreendido como uma profissão feminina, e que envolve as práticas de maternagem sociale/ou de cuidado/educação. Sobre esse aspecto, Cerisara (2002, p. 64) esclarece:

Um fator que agudiza essas posturas ambíguas das trabalhadoras assalariadas, ao mesmo tempo referidas à vida doméstica e às relações familiares, é a dupla inserção dessas mulheres na instituição de Educação Infantil, como profissionais e como mães.

Sayão (2005, p. 196), também faz referência à dupla presença, dupla experiência:

[...] a experiência pessoal no plano doméstico ou privado - com a criação dos/as filhos/as - poderia estar articulada de alguma maneira com a identidade profissional situada na esfera pública - na instituição - por essa razão procurei problematizar aspectos concernentes à dupla presença: na casa e na creche, e à dupla experiência: maternidade/paternidade e docência.

A profissão docente, no âmbito da Educação Infantil, também se constitui pela relação entre o público e o privado, uma vez que "a experiência com a paternidade e a maternidade habilita de certa maneira para a profissão, [...] a paternidade pode ser enriquecida pelas experiências obtidas com funções inerentes aos cuidados no âmbito da maternagem" (SAYÃO, 2005, p. 198).

Ao fazer referência ao professor de Educação Infantil com relação ao cuidado das crianças, a autora reitera:

A atuação de homens no cuidado das crianças pequenas parece ampliar a concepção do gênero, porque confere outros sentidos à ideia reducionista de papéis/funções específicas para homens e mulheres posto que docentes podem exercer o papel ou a "função materna", ampliando-a para a compreensão dos diferentes modos pelos quais o gênero opera estruturando o social e com isso ressignificando a fixidez de tais papéis e funções (SAYÃO, 2005, p. 192-193).

Importante ressaltar que essa ideia "reducionista da divisão de papéis e funções específicas para homens e mulheres" é acentuada no século XIX (PERROT, 1988, p. 178). "Cada sexo tem sua função, seus papeis, suas tarefas, seus espaços, seu lugar quase predeterminados, até em seus detalhes. [...] Ao homem, a madeira e os metais. À mulher, a família e os tecidos” (PERROT, 1988, p. 178). A relação entre os papeis domésticos privados das mulheres e papeis profissionais nos contextos públicos de educação feminino e profissional, é radicada no tempo histórico:

Desde a época romana, as pessoas que constituem as primeiras figuras do que será a função especializada diferente da dos pais para influir sobre o menor mostram a ambiguidade da mistura entre a continuidade da relação maternal afetiva da ama-de-leite e a severidade mais própria da mãe, pois sua missão é a de substituir ou prolongar, segundo se observa, a ambas. Devem cuidar dos menores, ter estreitas relações afetivas com eles, ao mesmo tempo em que vão formando o caráter. A ama-de-leite amamenta, ama e cuida como mãe. A preceptora (a que instrui no lar) é um membro a mais da família, e, do mesmo modo que a criadagem, vive às vezes com ambas, ensina dentro do espaço familiar, estende o cuidado à vida das crianças fora do estrito perímetro da casa senhorial e se relaciona com elas com carinho próprio da mãe e com a disciplina “paternal". É um papel que está entre a mãe e a professora, entre o ofício profissional assalariado e o serviço doméstico exercido em um espaço-tempo protoescolar no meio familiar, e que começa a diferenciar as funções educacionais da família e dos ambientes(SACRISTÁN 2005, p. 128). 
Nesta direção, para maior compreensão da construção sócio-histórica da docência na Educação Infantil, identificada até aqui ao gênero feminino, à maternidade, ao cuidado e à filantropia, destacam-se os estudos de Rocha (2012) e Batista (2013), que trazem, nas suas análises, indicativos sobre as origens de uma constituição profissional feminina. Neste sentido, o esforço em analisar as bases teóricas acerca dessas profissionais, identidade e gênero, alia-se às preocupações com as origens desta docência, produzindo novos questionamentos críticos e de investigações sobre o processo histórico que constitui a docência na Educação Infantil. Persistir na compreensão e debate sobre o caráter social das relações de gênero implica reconhecer que o gênero constitui-se pelas dimensões biológicas e históricas.

\section{Origens de uma constituição profissional feminina}

Para elucidar a origem da docência na Educação Infantil como constituição profissional feminina, é necessário refletir sobre as determinações políticas, sociais e econômicas vinculadas às relações do trabalho operário das mulheres. Esta reflexão evidenciará a profunda desigualdade social gerada pelas contingências do processo de industrialização e urbanização que produz, ao mesmo tempo, uma elite detentora dos meios de produção e, consequentemente, um contingente de trabalhadores e trabalhadoras suscetíveis às condições de exploração e pobreza. O discurso em relação ao ideal de mãe educadora afável, bondosa, paciente, carinhosa, com espírito cristão, é endereçado às mães das classes sociais abastadas, e moldará o exemplo para educadoras que assumirão a educação das crianças, filhas de famílias operárias. De acordo com Ferreira (2000, p.184),

[...] o ideal veiculado ideologicamente pelos discursos científicos, da mãe devotada ao cuidado e educação dos filhos, apresenta-se como um sonho impossível face à precariedade das condições de vida e assistenciais das mulheres operárias, que se vêm obrigadas a deixar essas funções a outras mulheres. Trabalhar significa não poder zelar por seus filhos e isso implica na necessidade de a criança ser educada no interior de instituições públicas por profissionais adequados/as para o efeito. É decorrente deste contexto que emerge a necessidade de uma nova profissão, as educadoras de infância, as quais vão ser consideradas, na ausência das mães, as suas substitutas mais imediatas da família.

A gênese dessa nova profissãode educadoras de infância, no Brasil, é identificada nos artigos da revista $A$ mãi de familia ${ }^{5}$, no estudo realizado por Rocha $(2012)^{6}$, a partir dos artigos da mencionada revista, no primeiro texto publicado no Brasil sobre creche: Vinelli, K., A créche - Asylo para a primeira infância, (no1 - Anno 1, 1987,p. 3-4). Neste artigo, o autor faz uma defesa da Creche e define suas origens e funções, citando a primeira instituição desse tipo, fundada em Paris, em 1844, por Jean Baptiste Firmin Marbeau, e o livro Das creches ou meio de diminuir a miséria e aumentar a população, publicado no Rio de Janeiro, em 18797 .

As mulheres das classes abastadas são chamadas para, junto aos médicos, assumir as atividades de proteção e assistência às crianças pobres, em uma perspectiva caritativa e filantrópica. A partir do no5 da

\footnotetext{
${ }^{5}$ A mãi de familia- jornal quinzenal voltado para as senhoras da sociedade carioca, com fins de instrução e cultura.

${ }^{6}$ Levantamento de fontes realizado para a pesquisa de estágio pós-doutoral: A invenção da Professora de Educação infantil, 2012, não publicada.

7 Jean Baptiste FirminMarbeau (18 de maio de 1798- 10 de outubro de 1875) era um francês filantropo que foi pioneiro, um precursor da moderna creche. Conhecido por ter fundado a primeira creche, que abriu em Paris, em 14 de novembro de 1844.
} 
revista (Anno 3, 1881, p. 35), seu editor, o doutor Carlos Costa, propõe a união das senhoras para a fundação de uma Associação Protetora das Crianças - créches ou asylos, de forma a proteger as crianças abandonadas nas ruas, sobretudo aquelas nascidas após a Lei do Ventre Livre:

Eis já uma primeira necessidade de uma associação que fosse composta de Senhoras, que comprehendam os sagrados deveres da maternidade e que tivessem o elevado encargo de levarem ao seio d'essas familias infelizes o conselho e auxilio salutares.

Para entender as marcas históricas deste processo de consolidação da Creche no Brasil é importante lembrar que há uma simultaneidade temporal na implantação destas instituições e na dos Jardins de Infância. Em 1883, publica-se o artigo A educação e o Jardim de Infância, do doutor Menezes Vieira, que anuncia a criação de comissão, pelo Governo Imperial, para angariar fundos para este fim. Traz o texto: "O Jardim de Infância, os asylos, escolas maternais ou kindergarten, como quiserem denomina-los, são remédio eficaz, heroico [...]. Na França em 1857, haviam 3.000 salas de asylos...]". Em continuação do artigo (p. 95, no9 - Anno 4, 1883), o autor apresenta o Jardim de Infância como emancipação da mulher, afirmando: "Convicto que a mulher é a única a substituir a mãi8".

A presença e ação das mulheres, seu papel social na educação das crianças como guardiãs dedicadas e carinhosas é, também, exaltada pelo doutor Carlos Costa, ao propor que: "melhor ninguém poderá exercer esses encargos que as Irmãs de Caridade. Como dedicação, como carinho pelas crianças, como vigilância”. Essa ideia é evidenciada também na Quinta Carta ao Ministro da Justiça e proteção às crianças

O pessoal das créches se compõe: de uma vigilante ou diretora; de mulheres encarregas de embalar as crianças (berceuses, embaladeiras, berçaristas) e de creadas. As berceuses têm como ocupação tomar conta das crianças. De accordo com o decreto ministerial de que falaremos, cada berceuse deve tomar conta de seis creanças. Porém, as maiores de um anno de idade, não tendo necessidade, na prática, de constante vigilância, este decreto nunca é observado e cada berceuse se encarrega de doze crianças. As creadas se ocupam dos trabalhos da cozinha, do aceio do edifício, etc. O estabelecimento deve ter um médico [...]. Quanto ao pessoal em serviço das créches, entendo que melhor ninguém poderá exercer esses encargos que as Irmãs de Caridade. Como dedicação, como carinho pelas creanças, como vigilância, (...) De sorte que eu proporia que as berceuses fossem irmãs de caridade, e as creadas, as que estas escolhessem fossem elas que as dirigissem, sob a fiscalização de uma senhora o conselho, que ficariam semanas n'esse trabalho" (COSTA, 1888, p. 100-101).

A pesquisa realizada por Batista (2013), intitulada A emergência da docência na Educaşão Infantil no estado de Santa Catarina - 1908 a 1949, evidencia que a circulação de ideias na capital do país é identificada, também, na constituição das primeiras instituições e na definição das profissionais do Jardim de Infância e Creches no estado de Santa Catarina. Nesse estudo são abordadas as dimensões da docência na Educação Infantil que emergem dos modos como foi gestada, a partir de iniciativas religiosas, filantrópicas, médicohigienistas, empresariais, em diferentes contextos geográficos, históricos e políticos.

São apresentadas as iniciativas de Jardim de Infância e Creche vinculadas à ação direta das mulheres, geralmente religiosas, em instituições voltadas para educação, saúde e assistência social. Às religiosas (luteranas e católicas) que tinham uma vida ativa junto à igreja e/ou vinculadas às congregações

${ }^{8}$ Neste número da revista, Domingos J. B. D'Almeida já cita o método intuitivo de Friedrich Froebel (1782-1852), criador do primeiro Jardim de Infância. 
femininas era destinada a tarefa de atender às crianças, reafirmando o ethos religioso orientado pelo dever e fundamentado na obediência às regras religiosas, que passam a embasar uma docência como ofício moral. O tom implícito na educação religiosa luterana caracteriza a função e o papel da mãe e professora afetuosa e maternal (BATISTA, 2013).

A criação do Jardim de Infância está diretamente vinculada às Congregações Religiosas Femininas Católicas e às Associações de Senhoras Evangélicas, em diferentes regiões do estado, colonizadas, sobretudo, por imigrantes alemães e italianos. As mulheres de confissão luterana, organizadas nas associações, foram as pioneiras na fundação do Jardim de Infância no estado.

A atuação, para além do âmbito doméstico familiar, concentrava-se nas atividades consideradas tipicamente femininas, como trabalho filantrópico, apoio aos doentes, à maternidade e à educação das crianças, pois as mulheres com boa educação religiosa seriam mais aptas para a educação dos filhos, para o trabalho do lar, para as escolas, para os trabalhos assistenciais e filantrópicos. Como indica Farias (2016, p. 16 , grifos do autor):

Impedidas de acessar os espaços de poder na hierarquia das Igrejas, às mulheres, foram reservados lugares que reforçavam as habilidades tipicamente femininas, pois prevalecia junto aos protestantes a certeza de que "mulheres com boa educação religiosa seriam mais aptas para o lar, para as escolas, para os trabalhos assistenciais e para o missionarismo".

A formação da mulher luterana incluía estudos específicos para atuar no Jardim de Infância, com a ressalva de que esta formação era direcionada para as alunas senhoras, com destaque para o aprofundamento dos conhecimentos das áreas da educação:

$\mathrm{Na}$ Franenschule são oferecidos dois cursos da Escola de Senhoras e da Escola de Economia Doméstica, onde é introduzido o ensino tanto teórico quanto prático, em todos os ramos da administração familiar. Apenas às alunas "senhoras" eram ministradas as aulas de educação, psicologia e metodologia do jardim-de-infância, apoiadas por atividades práticas com os pequenos do jardim da Escola Nova e do Johannastift. Essas aulas são ministradas de tal forma que habilitarão as alunas para a função de professora, ou seja, diretora do jardim-de-infância. Contudo, a formação profissional não se encontra em primeiro plano, seu principal objetivo é ajudar a aluna no desenvolvimento primordial da sua feminilidade, da felicidade espiritual e do seu sentimento maternal (BLUMENAU EM CADERNOS, 2001, p. 48-49).

A maternidade é considerada a mais digna tarefada mulher luterana, que deve se preparar, adquirir conhecimento, antes de tudo para educar seus filhos por meio dos princípios cristãos,muito embora o objetivo maior estivesse entrelaçado com a formação da feminilidade e do sentimento maternal. Ao "definir a "boa mãe" que é educadora e a Educadora como profissional da educação da infância", circunscreve as funções da mulher à educação (FERREIRA, 2000, p. 182).

É importante destacar que o prolongamento da função de cuidado da mãe no Jardim de Infância é uma premissa de Froebel, criador dos Kindergarten, que

considerava que a melhor professora para as crianças pequenas era a "mãe conscienciosa" devendo adquirir e utilizar as condições naturais das boas mães. Deste modo estabelecia-se não só um modelo educacional para meninos e meninas, mas além disso se prolongava o papel da mulher na figura das professoras (SACRISTÀN, 2005, p. 129). 
A influência froebeliana destaca-se no Jardim de Infância de confissão luterana como agente da educação moral direcionada pelo espírito feminino que se estende aos contextos privados da família, como forma de evitar as supostas más influências advindas de outros contextos. Também podemos afirmar que o Jardim de Infância, nesta perspectiva, configurava-se como espaço de uma educação rígida, no sentido de evitar a preguiça e a indolência, e ensinar os verdadeiros valores do tempo e do trabalho como princípios de uma ética protestante:

Ócio e prazer, não só; só serve a ação, o agir conforme a vontade de Deus inequivocamente revelada a fim de aumentar sua glória. A perda de tempo é, assim, o primeiro e em princípio o mais grave de todos os pecados. Nosso tempo de vida é infinitamente curto e precioso para "consolidar" a própria vocação. Perder tempo com sociabilidade, com "conversa mole", com luxo, mesmo com o sono além do necessário à saúde - seis, no máximo, oito horas - é absolutamente condenável em termos morais. [...] o tempo é infinitamente valioso porque cada hora perdida é trabalho subtraído ao serviço da glória de Deus (WEBER, 2004, p. 143).

O protagonismo das mulheres luteranas como responsáveis pela educação das crianças no âmbito doméstico e público - Jardim de Infância - é investido de poder social, uma vez que assumem para si a tarefa de manter a harmonia familiar e educar as crianças a partir dos preceitos da moral, da virtude, do valor do trabalho, do amor à pátria. Resguardar a naturęa infantil e preservar as crianças das influências externas, preparando-as para a inserção futura na sociedade, eis o poder das mulheres na vida social. A formação espiritual e moral dos pequenos respondia à urgência de uma nação civilizada, que exigia sujeitos obedientes, saudáveis e produtivos. Neste sentido, o princípio da natureza feminina como boa mãe é considerado como potência civilizatória da infância, tanto no âmbito do espaço privado - doméstico -, quanto no espaço público - Jardim de Infância. Ambos separados da esfera política, reservada aos homens, cujo papel social é definido pelo

discurso naturalista, que insiste na existência de duas "espécies" com qualidades e aptidões particulares. Aos homens, o cérebro, [...] a inteligência, a razão lúcida, a capacidade de decisão. Às mulheres, o coração, a sensibilidade, os sentimentos (PERROT, 1988, p. 177)

Essa exclusão das mulheres do âmbito da política é evidenciada nas associações femininas evangélicas de caráter filantrópico, em que a inciativa e organização conta com a presença dos pastores que assumiam um lugar ativo e majoritário nas decisões, não somente ligadas à Igreja, também na comunidade. Ou seja,

A Igreja Luterana compreendia como um espaço tipicamente feminino o ambiente doméstico, do lar e as funções desempenhadas pelas mulheres na igreja deveriam ser uma extensão desses papéis. Assim, a igreja luterana compreendia que tudo o que estivesse relacionado ao público e com a palavra era naturalmente atribuído aos homens (FARIAS,2016, p.17).

Outras iniciativas de Jardim de Infância no estado de Santa Catarina constituíram-se, também, como uma atividade assumida por diferentes Congregações Religiosas Femininas de confissão católica. O espírito cristão, os sentimentos nobres das Irmãs de Caridade, aliados à feminilidade e à formação religiosa, são critérios que habilitam as Irmãs para atuarem no Jardim de Infância. A abnegação, a entrega, a devoção e atitudes acolhedoras como qualidades tipicamente femininas eram, também, enfatizadas e 
compreendidas como pré-requisitos que definiam a profissional responsável pelo cuidado e educação das crianças pequenas.

Todavia, os Jardins de Infância, na sua maioria ligados à Igreja Católica, foram criados e amplamente propagados por grupos compostos por homens influentes da sociedade civil e da Igreja Católica (BATISTA, 2013). À margem dos poderes e decisões políticas, as Mulheres-Irmãs protagonizam as práticas educativas no interior das instituições, lugar destinado a elas.

A religião é reconhecidamente um espaço de ocultamento das mulheres. A ocupação dos espaços públicos e privados nas igrejas ainda é definida com base nas hierarquias de gênero, com as mulheres desempenhando, na maioria das vezes, a função de auxiliares dos homens, em papéis tidos como "naturalmente" femininos (FARIAS,2016, p. 17).

As iniciativas de Creche no estado de Santa Catarina (1936-1943) partem de diversos agentes sociais - damas da sociedade vinculadas à Legião Brasileira de Assistência, Círculo Operário Católico - e industriais. As diversas formas de atendimento no campo da assistência e educação à infância e à maternidade eram desenvolvidas no âmbito da caridade e da filantropia, sob as orientações médicohigiênicas difundidas pelo Departamento Nacional da Criança (DNCr), órgão criado a partir do Decreto Lei 2024, de 17 de fevereiro de 1940. Este decreto fixa as bases da organização da proteção à maternidade, à infância e à adolescência em todo o país e, em relação à educação da pequena infância, cria medidas de cunho político, social e assistencial.

A presença das Irmãs de Caridade, enfermeiras e visitadoras, na condução da assistência e educação das crianças e das mães, remete para uma experiência de docência na Creche exclusivamente feminina, embora orientada e supervisionada por médicos e especialistas em puericultura. Em uma das iniciativas de Creche fundada pelo Círculo Operário Católico na cidade de Joinville, no ano de 1936, evidencia-se, nas palavras do padre Kolb, a profícua atividade das Irmãs de Caridade São Vicente de Paulo:

O que tem sido a ação humanitária destas humildes servas de Deus em Joinville é de todos sabido. Atestam-na brilhantemente o cuidado e o zelo de que são tratadas as criancinhas recolhidas à creche. Tudo nesta casa de caridade evidencia o elevado espírito cristão e os sentimentos nobres das irmãs que a dirigem (KOLB, [1941/42],s/p).

No Centro de Puericultura Beatriz Ramos, instalado na Capital de Santa Catarina, no ano de 1943, as crianças de 0 a 1 ano eram objeto de intervenção dos serviços de higiene infantil, que ficavam sob a responsabilidade de uma enfermeira e sob vigilância do puericultor e do pediatra. $O$ papel social das enfermeiras era enfatizado como "mensageiras do bem, instruídas, disciplinadas e disciplinadoras" - a criação dos seus serviços era “uma feliz providência para o Brasil” (FIGUEIREDO, 1938, p. 69).

A política de amparo e assistência à maternidade e à infância no Estado previa, também, a constante vigilância às mães pelos postos de puericultura, através do "serviço de visitadora-atendente", e reuniões de mães com intuito de ensiná-las como cuidar e educar seus filhos. Se foi pela política de assistência que as mulheres, em especial as pobres que, por vezes, foram julgadas incompetentes para cuidar dos seus filhos, também era por esta mesma política, em larga medida empreendida pela LBA, que 
as mulheres da sociedade florianopolitana ${ }^{9}$ se constituíram em agentes essenciais ao projeto de Nação, baseado no modelo médico-higiênico legitimando a maternidade como função pública e principal função social feminina. A força atribuída à mulher, em especial a mulher das classes abastadas, como redentora e veiculadora de um projeto civilizatório evidenciava os predicados tipicamente femininos, suas aptidões práticas de promover a educação das famílias pobres, cujo alvo eram as mães e as crianças. Cabe lembrar que tal política de proteção à maternidade e à infância como questão científica, com base na higiene e puericultura, remete ao início do século XX, com a criação do Instituto de Proteção à Infância do Rio de Janeiro. A aliança entre associações femininas de beneficência e médicos higienistas é evidenciada na comunicação feita pelo doutor Arthur Moncorvo Filho sobre o problema da infância, apresentada ao II Congresso Internacional Feminino:

Si médicos, filantropos, estadistas, sociologos e hygienistas, em grande numero se quedam a dirigir suas benevolas vistas para o palpitante problema em causa, não deixa de ser verdade que á Mulher deve estar reservado o principal papel como educadora, como insinuadorados bons preceitos, como guia para a vida saudável e feliz, como propagandista dos conselhos para evitar os males funestos como o jogo, o alcool, etc, como a grande inspiradora das melhores acções na defesa dos direitos que á criança assistem, como ficou evidenciado em 17 de maio de 1927, na celebre "Declaração de Genebra" aprovada pela Sociedade das Nações (MONCORVO FILHO, 1930, p. 4 ).

A vinculação das mulheres das classes alta e média urbana ao movimento de assistência em favor da criança e aconselhamento das famílias pobres evidencia distinções de gênero que reforçavam a preleção sobre a mulher: benevolente, inspiradora, condutora das ações e ideias formuladas e estabelecidas pelos homens da política e da ciência. A mulher, pela sua vocação biológica para a maternidade, torna-se naturalmente instrumento de persuasão das famílias pobres, ou seja, aconselhar o maior rigor nas regras de higiene infantil, em benefício da grande obra civilizatória de regeneração da infância.

Do mesmo modo, inscreve-se a experiência da Creche da Cia. Hering, fundada na cidade de Blumenau, em 1945, como cumprimento das exigências contidas na então recente Consolidação das Leis do Trabalho (CLT - Lei 5.452/1943). O atestado de admissão da encarregada da Creche, emitido pelo doutor Abelardo Vianna, chefe do Departamento de Saúde Pública e pelo doutor Affonso Balsini, Chefe da Higiene Infantil, faz referência à formação exigida para trabalhar no berçário: "Atestamos que a Srta. Selma Bickhardt, branca, brasileira, fez um completo estágio em nossa secção de higiene infantil, inclusive na cozinha dietética, estando perfeitamente apta para dirigir trabalhos de berçários e elaborar a alimentação dos lactentes" (BATISTA, 2013, p. 167). Os conhecimentos dos preceitos da puericultura e da higiene infantil serão indispensáveis ao exercício do cargo de encarregada da Creche, a fim de assegurar a fiel execução das ordens do médico puericultor em proveito das crianças (FIGUEIREDO, 1946).

As questões sobre a constituição profissional feminina no âmbito da Creche e Jardim de Infância, até aqui apresentadas, evidenciam a subordinação aos discursos médicos e religiosos, em uma clara relação

\footnotetext{
9 De acordo com Relatório da LBA do ano de 1945, no município de Florianópolis, "a lista de adesão posta à disposição de todas as senhoras e senhorinhas das diferentes classes sociais, logo após a assinatura da ata que marcou a fundação da Legião em nosso Estado, acusou de início, a assinatura de 678 legionárias. Dentro em pouco êsse número atingia a casa de 800 , e logo duplicava, quando a C.E. recebeu a adesão em peso, do Instituto 'Coração de Jesus', representado por sua ilustre Irmã Diretora, reverendíssimas Irmãs professoras e a totalidade das alunas dos cursos superiores do importante educandário" (RELATÓRIO LBA, 1945).
} 
hierárquica que põe em evidência as relações de gênero na constituição dessa profissão. A vinculação da disposição do trabalho das mulheres aos atributos considerados inatos ao seu sexo biológico favoreceu, de certo modo, seu ingresso nas profissões que exigem essas habilidades femininas, entre elas, o instinto maternal para a missão educadora e redentora, fator primordial do progresso.

É possível afirmar, também, de uma profissão feminina que exerce poder social, em detrimento do poder político econômico de seu tempo, uma evidência que se revela no fato de os nomes de médicos, pastores, padres, industriais, entre outros, figurarem como atores principais das iniciativas e orientações das ações no Jardim de Infância e Creche, enquanto muitas das identidades de mulheres que atuavam diretamente com as crianças eram consideradas coadjuvantes e/ou ficavam na obscuridade, sob denominações genéricas: irmãs, missionárias, irmãs religiosas, juvenistas, senhoras evangélicas, encarregadas da Creche e/ou empregadas da Creche. Em outras palavras,

Os discursos e práticas normativos direcionados às mulheres constituem-se discursos masculinos "sobre as mulheres e para as mulheres", devendo ser vistos como a manifestação de um grupo que objetiva dar efetividade a um conjunto de representações, ou seja, que envolvem práticas, razões, códigos, finalidades e destinatários particulares, que são difundidos com o objetivo de legitimar escolhas e condutas, reforçando a identidade desse grupo em um espaço de poder e dominação (FARIAS, 2016, p. 33).

Nesta direção, Kuhlmann também chama atenção para o lugar social atribuído à mulher, muito mais na condição de coadjuvante dos processos socioeducativos idealizados pelos homens, em especial, médicos e puericultores:

A participação da mulher na assistência era estabelecida numa linha de auxiliares da intervenção dos homens. As mães burguesas, as esposas e parentes dos promotores de associações assistenciais eram postas como aliadas dos médicos na tarefa de difusão dos novos comportamentos exigidos para a função materna, atuando como modelos junto às mães trabalhadoras. Esse movimento de promoção e subordinação da mulher pode ser verificado na ocupação de cargos de caráter secundário na composição das associações, e também no nome atribuído à creche fundada pelo IPAI-RJ, em 1908, Creche Sra. Alfredo Pinto: o nome da homenageada ficou à sombra do seu marido, chefe de polícia do Distrito Federal (1998, p. 92).

É importante considerar que ainda sabemos pouco sobre as profissionais que atuaram diretamente no trabalho educativo com as crianças pequenas. Segundo Perrot (1988, p. 186), “[...] o silêncio sobre a história das mulheres também advém do seu efetivo mutismo nas esferas políticas, por muito tempo privilegiadas como locais exclusivos de poder." Contudo, convém ressaltar que

As mulheres, não são passivas, nem submissas. A miséria, a opressão, a dominação, por reais que sejam, não bastam para contar a sua história. Elas estão presentes aqui e além. Elas são diferentes, se afirmam por outras palavras, outros gestos. $\mathrm{Na}$ cidade, na própria fábrica, elas têm outras práticas cotidianas, formas concretas de resistência - à hierarquia, à disciplina - que derrotam a racionalidade do poder, enxertadas sobre seu uso próprio do tempo e do espaço. Elas traçam um caminho que é preciso reencontrar. Uma história outra. Uma outra história (PERROT, 1988, p. 212).

Vale reiterar que a experiência materna, em uma perspectiva mais ampla, como uma experiência que afeta as relações sociais e culturais de homens e mulheres no âmbito privado - doméstico, seja 
potencializada e/ou incorporada à profissão docente. Isto exige compreender a natureza complexa dessa profissão,

[...] como uma forma particular de trabalho sobre o humano, ou seja, uma atividade em que o trabalhador se dedica ao seu objeto de trabalho, que é justamente um outro ser humano, no modo fundamental da interação humana. O importante aqui é compreender que as pessoas não são um meio ou uma finalidade do trabalho, mas a matéria-prima do processo do trabalho interativo e o desafio primeiro das atividades dos trabalhadores (TARDIF; LESSARD, 2009, p. 8).

As reflexões poderão contribuir com melhores definições para esse segmento profissional que está em processo de construção. A estruturação histórica da constituição da docência e dos serviços voltados para o cuidado e a educação das novas gerações, suas políticas e práticas de atendimento à infância, contribuem para o nosso entendimento de que a "categoria de gênero é uma dimensão decisiva da organização da igualdade e desigualdade em nossa sociedade, já que as estruturas hierárquicas repousam sobre percepções generalizadas da relação pretensamente natural entre masculino e feminino" (CERISARA, 2002, p. 28).

Neste sentido, compreender a categoria de gênero como constitutiva da docência na Educação Infantil poderá ampliar as condições de analisar criticamente a condição de subalternidade de gênero, no sentido da tomar consciência da ação e do papel como agente que reproduz. Contudo, também transforma, em uma perspectiva da emancipação das mulheres e homens envolvidos com a educação da pequena infância. Para tanto, continua presente a necessidade de desnaturalizar as justificativas históricas pautadas nas desigualdades sociais entre homens e mulheres, pelas suas características biológicas. "Seja no âmbito do senso comum, seja revestido por uma linguagem 'científica', a distinção biológica, ou melhor, a distinção sexual, serve para compreender — e justificar — a desigualdade social” (LOURO, 1997, p.21)

Importante considerar que, a história sobre as experiências das mulheres (freiras, diaconistas, enfermeiras, professoras, damas de caridade), sua formação e atuação direta e indireta com as crianças, ainda exige um trabalho de garimpagem de fontes que revelem outras evidências e que venham a contribuir para ampliar a história da constituição da docência na Educação Infantil. Trata-se de reconstruir as experiências daquelas mulheres que se lançam no espaço da educação das novas gerações, cuja existência pode ter sido secundarizada em detrimento de um projeto de sociedade assentado na subalternidade das mulheres e crianças.

Dar visibilidade para o lugar social das mulheres e dos homens, desnaturalizar as concepções históricas que justificam as desigualdades sociais e de gênero, nos faz continuar problematizando aspectos que norteiam a profissão e a especificidade da docência na Educação Infantil, considerando que ainda depende de melhores definições acerca do trabalho desenvolvido com crianças de 0 a 6 anos de idade. 


\section{Referências}

ALBUQUERQUE, M. H. Formação docente para Educação Infantil no Brasil:configurações curriculares nos cursos de pedagogia. 2013. 193f.Dissertação (Mestrado em Educação) - Universidade Federal de Santa Catarina, Florianópolis, 2013.

BATISTA, R. A emergência da docência na Educação Infantil no estado de Santa Catarina:1908 1949. 2013. 198f. Tese (Doutorado em Educação) Universidade Federal de Santa Catarina, 2013.

BLUMENAU EM CADERNOS. TOMO XI, III, n. 09/10, set/out, 2002.

BONETTI, Nilva. 2004. A especificidade da docência na educação infantil no âmbito de documentos oficiais após a LDB 9394/1996. (Dissertação de mestrado). Universidade Federal de Santa Catarina. Florianópolis/SC.

CERISARA, Ana Beatriz. A construção da identidade das professoras de Educação Infantil:entre o feminino e o profissional. 1996. 184 f. São Paulo, USP, Tese (Doutorado em Educação) Universidade de São Paulo, São Paulo, 1996.

2008.

Professoras de educação infantil:entre o feminino e o profissional. São Paulo: Cortez,

COSTA, C. Sociedade Protetora das Crianças. A Mãi de família: jornal scientíficolitterário ilustrado, Rio de março, a. 3, n. 5, p. 35, Julho1881.

Protecção as Crianças. A Mãi de família:jornal scientíficolitterário ilustrado, Rio de Janeiro, a.10, n. 13, p. $99-100$, Julho1888.

DUARTE, F. Professoras de bebês: as dimensões educativas que constituem a especificidade da ação docente. 2011. 292f. Dissertação (Mestrado em Educação) - Universidade Federal de Santa Catarina, Florianópolis, 2011.

FARIA, Ana Lucia Goulart; PALHARES, Marina. Educação Infantil pós-LDB. São Paulo: Autores Associados, 1999.

FARIAS, M. N. de. Liga de Senhoras Luteranas do Brasil (LSLB): relações de gênero e poder no protestantismo brasileiro. 2016. 249f. Tese (Doutorado em História) - Universidade Federal da Grande Dourados, Dourados, 2016.

FERNANDES, T. M. Professora de Educação Infantil: dilemas da constituição de uma especificidade profissional. Um estudo sobre a produção científica brasileira (1996-2009). Dissertação (Mestrado em Educação). Universidade Federal de Santa Catarina, Florianópolis, 2010.

FERREIRA, M. M. Salvar Corpos, forjar a razão: contributo para uma análise crítica da criança e da infância como construção social em Portugal: 1880-1940. Porto-PT: Instituto de Inovação Nacional, 2000.

FIGUEIREDO, G. de. Como prospera o bebê. Rio de Janeiro: F. Briguiet\& Cia. Editores, 1938.

FIGUEIREDO, Gastão de. Creche. 2a. Edição. Rio de Janeiro: Ministério da Educação e Saúde/ Departamento Nacional da Criança - Imprensa Nacional, 1946. Coleção DNCr. no 95. 
FORMOSINHO, Júlia Oliveira. O desenvolvimento profissional das educadoras de infância: entre os saberes e os afetos, entre sala e o mundo. In: MACHADO, Maria Lúcia de A. (org.) Encontros e desencontros em educação infantil. São Paulo: Editora Cortez, 2002.

HADDAD, Lenira; CORDEIRO, Maria Helena; MONACO, Gregóry Lo. As tarefas do professor de educação infantil em contextos de creche e pré-escola: buscando compreender tensões e oposições. Educação \& Linguagem v.15 n. 25. 134-154. 2012.

KISHIMOTO, Tizuko Morchida. Encontros e desencontros na formação profissional de educação infantil. In: MACHADO, Maria Lúcia de A. (org.) Encontros e desencontros em educação infantil. São Paulo: Editora Cortez, 2002.

KOLB, A. Histórico do Círculo Operário através da imprensa. Fatos e não palavras. Amparando os proletários catarinenses. Livros ㄲo3 - [1941/42]

KUHLMANN JUNIOR, Moysés. Infância e educação infantil: uma abordagem histórica. Porto Alegre: Mediação, 1998.

KRAMER, Sônia. Formação de profissionais da educação infantil: questões e tensões. In: MACHADO, Maria Lúcia de A. (org.) Encontros e desencontros em educação infantil. São Paulo: Editora Cortez, 2002.

LOURO, G. L. Gênero, sexualidade e educação: Uma perspectiva pós-estruturalista. Petrópolis, Rio de Janeiro: Vozes, 1997.

MANTOVANI, Susanna; PERANI, Rita M. (1999). Uma profissão a ser inventada: o educador da primeira infância. Pro-posições, vol. 10, n. 1 [28]. Campinas: UNICAMP, p. 75-98.

MONCORVO FILHO, Carlos A. Algumas considerações sobre o problema da infância. Publicação do Departamento da Criança do Brasil no79. Rio de Janeiro, 1930, p. 4.

OLIVEIRA, Zilma Moraes Ramos; SILVA, Ana Paula Soares da; CARDOSO, Fernanda Moreno. Construção da identidade docente: relatos de educadores de educação infantil. Cadernos de Pesquisa (Fundação Carlos Chagas), v. 36, p. 547-571, 2006.

PERROT, M. As mulheres, o poder a história. In: Os excluídos da história: operários, mulheres e prisioneiros. Tradução: Denise Bottmann. Rio de Janeiro: Paz e Terra, 1988. p.167-184.

RIVERO, Andréa Simões. 2001. Da educação Pré-Escolar à Educação Infantil: um estudo das concepções presentes na formação dos professores no curso de pedagogia. Dissertação (Mestrado). PPGE/UFSC.

ROCHA, E. A. C. A invenção da Professora de Educação Infantil. Relatório de pesquisa de estágio pós-doutoral. PPGE/PUC-RJ, 2012.

SACRISTÁN, J. G. O aluno como invenção. Porto Alegre: Artmed, 2005.

SAYÃO, D. T. Relações de gênero e trabalho docente na Educação Infantil: um estudo de professores em creche. 2005. 273 f. Tese (doutorado) - Universidade Federal de Santa Catarina: PPGE, Florianópolis, 2005.

TARDIF, Maurice. Saberes docentes e formação profissional. 9aed. Petrópolis-RJ: Vozes, 2008. 
TARDIF, Maurice; LESSARD, Claude. $\mathbf{O}$ trabalho docente: elementos para uma teoria da docência como profissão de interações humanas. 4aed. Petrópolis-RJ: Vozes, 2008.

SCHMITT, R. V. As relações sociais entre professoras, bebês e crianças pequenas: contornos da ação docente. Tese (Doutorado). Universidade Federal de Santa Catarina, Florianópolis, 2014.

TRISTÃO, F. C. D. Ser professora de bebês: um estudo de caso de uma creche conveniada. 2004. 206f. Dissertação (Mestrado em Educação) - Universidade Federal de Santa Catarina, Florianópolis, 2004.

WEBER, Max. A ética protestante e o “espírito” do capitalismo. São Paulo: Cia das Letras, 2004.

VINELLI, K. A CRECHE (Asylo para a primeira infância). A Mãi de família: jornal scientíficolitterário ilustrado, Rio de Janeiro, janeiro, a. 1, n. 1, p. 3-4, 1979.

A CRECHE (Asylo para a primeira infância). A Mãi de família: jornal scientífico litterário ilustrado, Rio de Janeiro, janeiro, a. 1, n. 2, p. 15-16, 1979. 